\title{
DEFININDO O CONHECIMENTO ARQUIVÍSTICO: ESTRUTURAS CONCEITUAIS
}

\author{
DEFINING ARCHIVAL KNOWLEDGE: CONCEPTUAL \\ FRAMEWORKS
}

\author{
Natália Bolfarini Tognolia \\ Ana Célia Rodrigues ${ }^{b}$ \\ José Augusto Chaves Guimarãesc
}

\begin{abstract}
RESUMO
Introdução: Apesar de ter o princípio da proveniência como seu elemento norteador, a organização do conhecimento arquivístico ainda prescinde de uma maior clareza conceitual de seu objeto - o conhecimento arquivístico - aspecto fundamental para a sedimentação dos estudos arquivísticos e de sua comunidade discursiva no âmbito da organização do conhecimento (OC). Objetivo: O presente artigo tem como objetivo a definição de uma estrutura conceitual para o conhecimento arquivístico a partir da teoria do conceito de Dalhberg. Metodologia: Revisão de literatura sobre organização do conhecimento na Arquivologia e sobre a Teoria Do Conceito. Resultados: A pesquisa estabeleceu um conceito nominal ou definiendum - conhecimento arquivístico analisando sua definição real, composta por três definiens: o conceito de fundo, o conhecimento da forma documental e o conhecimento do contexto de produção do documento. Conclusão: Ao final, reconhece-se que o conhecimento arquivístico pode ser definido como uma reunião três facetas indissociáveis na qual o vínculo arquivístico estará contemplado.
\end{abstract}

Descritores: Organização do conhecimento. Teoria do Conceito. Conhecimento arquivístico. Diplomática.

\footnotetext{
a Doutora pelo Programa de Pós-Graduação em Ciência da Informação da Universidade Estadual Paulista Júlio de Mesquita Filho (UNESP). Professora do Departamento de Ciência da Informação e do Programa de Pós-Graduação em Ciência da Informação da Universidade Federal Fluminense (UFF). E-mail: nataliatognoli@id.uff.br

b Professora do Departamento de Ciência da Informação e do Programa de Pós-Graduação em Ciência da Informação da Universidade Federal Fluminense (UFF). E-mail: anyrodrigues@yahoo.com.br

c Doutorado em Ciências da Comunicação pela Universidade de São Paulo (USP). Professor do Departamento de Ciência da Informação da Universidade Estadual Paulista (UNESP). E-mail: chaves.guimaraes@unesp.br
} 


\section{INTRODUÇÃO}

Recentemente, a Arquivologia que durante anos esteve ligada às searas histórica, administrativa e diplomática, vem dialogando mais proficuamente com as disciplinas que têm a informação e o conhecimento como objeto de estudo, encontrando nos campos da Ciência da Informação e da Organização do Conhecimento $(\mathrm{OC})$, um espaço de interlocução, notadamente a partir do que se conveio denominar de "conhecimento arquivístico".

A OC constitui-se em um espaço interdisciplinar efetivo (GARCÍA MARCO, 1995; HJØRLAND, 2008), onde áreas como a Ciência da Informação, Lógica, Linguística, Comunicação, entre outras, integram-se em termos de estruturas teóricas e metodológicas para apoiar o desenvolvimento de processos, produtos e instrumentos de representação e organização de documentos e de seus conteúdos informacionais.

Trata-se de descrever, representar, preencher e organizar documentos e representações de documentos, assim como assuntos e conceitos, tanto por pessoas quanto por programas (HJORLAND, 2008).

Durante a década de 1980, a área aprofunda sua busca por metodologias e efetiva sua interdisciplinaridade (até então majoritariamente ligada aos estudos de classificação em Biblioteconomia) notadamente a partir da criação, em 1989, da International Society for Knowledge Organization - ISKO, por Ingetraut Dahlberg, na trilha da até então Society for Classification, que desde os anos de 1970 reunia matemáticos, filósofos, estatísticos, linguistas e cientistas de informação (GUIMARÃES, 2017).

Em meados da década de 1990, Esteban Navarro (1995) defendia uma aproximação dos estudos arquivísticos à Organização do Conhecimento, considerando essa última um campo integrador, capaz de ir além da divisão tripartida entre as áreas de Biblioteconomia, Arquivologia e Documentação, pressupondo uma integração entre elas a partir do estudo das técnicas de armazenamento, tratamento e recuperação de documentos. Ainda, segundo o autor, não havia motivos para que os pesquisadores, as sociedades científicas e os congressos sobre organização do conhecimento ignorassem os arquivos 
em suas discussões, uma vez que os documentos de arquivo também são classificados e descritos.

Após as considerações de Esteban Navarro, as discussões sobre a integração dos processos de $O C$ às funções arquivísticas de classificação e descrição, permaneceram adormecidas na área por vinte anos, quando Guimarães e Tognoli (2015) recuperam as discussões sobre a Arquivologia no âmbito da $\mathrm{OC}$ em seu artigo sobre o princípio da proveniência enquanto uma abordagem de análise de domínio, onde acrescentam os estudos da proveniência às onze abordagens propostas por Hjorland (2002).

Ao propor o princípio da proveniência enquanto uma abordagem de análise de domínio, Guimarães e Tognoli (2015) justificam a própria organização do conhecimento arquivístico enquanto um domínio.

\begin{abstract}
É importante observar que a organização do conhecimento arquivístico tem seu núcleo na classificação (estrutural ou funcional) e nos procedimentos de descrição, com o objetivo de estabelecer prerrogativas de conhecimento. Essas prerrogativas são construídas de acordo com o contexto da criação dos documentos, com o objetivo de garantir seus valores probatórios e históricos. Considerando essas questões, a organização do conhecimento arquivístico torna-se um domínio composto por um conjunto de pesquisadores de diferentes partes e instituições do mundo, que integram um colégio invisível profundamente envolvido na construção de uma base epistemológica ao utilizar uma estrutura discursiva específica que funde a terminologia tradicional da arquivologia com aquela da Ciência da Informação (GUIMARÃES; TOGNOLI, 2015, p. 567).
\end{abstract}

Nesse contexto, destacam-se os recentes estudos de Tognoli, Guimarães e Tennis (2013), Guimarães e Tognoli (2015), Tognoli, Rodrigues e Guimarães (2019), Barros e Moraes (2012), Alencar e Cervantes (2019), Lehmkuhl et al. (2019), emergindo enquanto uma comunidade discursiva comprometida na construção de conhecimento teórico-metodológico que auxilie a Arquivologia na produção, organização e uso dos documentos de arquivo, notadamente a partir dos estudos da OC.

No entanto, apesar de ter uma comunidade discursiva em formação profundamente envolvida na construção das bases epistemológicas da área ao utilizar uma estrutura discursiva específica que une a terminologia arquivística àquela da $\mathrm{OC}$, a organização do conhecimento arquivístico, enquanto um 
domínio, ainda prescinde de uma maior clareza conceitual de seu objeto - o conhecimento arquivístico - aspecto fundamental para a sedimentação dos estudos arquivísticos e de sua comunidade discursiva no âmbito da organização do conhecimento $(\mathrm{OC})$.

\section{DEFININDO UM CONCEITO}

Um conceito pode ser compreendido como um conjunto de enunciados verdadeiros sobre determinado objeto, fixado por um símbolo linguístico. Segundo Dahlberg (1978, p. 102), cada enunciado apresenta um atributo predicável do objeto que, no nível de conceito, chama-se característica. Para que se compreenda como um universo científico-disciplinar formaliza-se teoricamente, faz-se necessário, portanto, o conhecimento dos conceitos que alicerçam a teoria científica.

Se apreendermos o conceito dentro da lógica e da razão científica, ele seria a delimitação necessária que a linguagem científica se apoia para a representação da realidade mediante uma simbologia criada pelo primado da exatidão, da sensibilidade e da consensualidade (intersubjetiva), na busca pela representação dos fenômenos da realidade" (RABELLO, 2008, p. 25).

Ao definir um conceito, são estabelecidos pressupostos indispensáveis na argumentação e nas comunicações verbais, elementos necessários na construção de sistemas científicos. A importância das definições evidencia-se, também, quando se tem em vista a comunicação internacional do conhecimento (DAHLBERG, 1978). Neste sentido, acredita-se que um conceito definido é um importante indicador do comportamento de determinada comunidade científica por ser fruto de uma teorização sistematizada que o consolida em um determinado tempo histórico e que expressa as formas de pensamento, práticas sociais, práticas profissionais, etc. (RABELLO, 2008, p. 33).

Dado esse contexto, ao buscar uma definição de conhecimento arquivístico, pretende-se fixar o conteúdo desse determinado conceito, limitando-o. De acordo com Dahlberg (1978), fazer uma definição equivale a estabelecer uma "equação de sentido", onde de um lado (à esquerda) encontrase aquilo que deve ser definido (o definiendum), que aqui entende-se ser o 
conhecimento arquivístico, e, de outro lado (à direita), aquilo pelo qual alguma coisa é definida (o definiens).

Ainda segundo a autora, as definições podem ser nominais e reais. A primeira diz respeito à fixação do sentido de uma palavra (ex. conhecimento arquivístico), enquanto que a segunda delimita a intenção de determinado conceito, ou seja, do que ele é composto, distinguindo-o de outros com idênticas características. "Podem distinguir-se dizendo que a definição nominal procura fixar o uso de determinada palavra enquanto que a definição real tem por finalidade apresentar o conhecimento contido em determinado conceito" (DAHLBERG, 1978, p. 106).

Uma vez definido o conceito nominal - o conhecimento arquivístico, enquanto fixação do uso da palavra - passamos à sua definição real que acreditamos ter como base o princípio de respeito aos fundos e o conhecimento da forma documental e do contexto de produção.

\section{ESTRUTURAS CONCEITUAIS DO CONHECIMENTO ARQUIVÍSTICO}

\subsection{O PRIMEIRO DEFINIENS: O CONCEITO DE FUNDO}

Em 2013, no artigo intitulado Diplomatics as a methodological perspective for archival knowledge organization, Tognoli, Guimarães e Tennis (2013) definiram conhecimento arquivístico como "[...] todo o conhecimento produzido por uma pessoa física ou jurídica e que está agrupado em um fundo documental." Ainda, segundo os autores

[...] os documentos agrupados em um fundo, refletem o conhecimento que foi produzido sobre uma determinada pessoa ou instituição, agindo três principais atores neste contexto: (1) o criador (autor), que é a pessoa física ou jurídica responsável pela criação dos documentos; (2) o usuário, que irá utilizar os documentos para fins probatórios, administrativos ou históricos e; (3) os intermediários, que são os arquivistas ou outras pessoas responsáveis pela organização dos documentos (TOGNOLI; GUIMARÃES; TENNIS, 2013, p. 205, tradução nossa).

Observa-se, portanto, que o conceito de fundo é o primeiro definiens do conhecimento arquivístico, uma vez que reúne em si todas as informações a respeito de uma determinada pessoa ou instituição, refletindo o conhecimento 
gerado em etapas anteriores, como a aplicação do método diplomático no momento da identificação arquivística.

Enunciado primeiramente em 1841, pelo francês Natalis de Wailly, o conceito propõe que os documentos sejam reunidos segundo o órgão, estabelecimento, família, ou indivíduo que os produziu, dando origem ao princípio de respeito aos fundos, segundo o qual documentos de uma mesma origem não poderiam ser misturados com outros de origens diversas e que sua ordem original, caso existisse, deveria ser preservada.

Na Prússia, em 1881, o princípio de respeito aos fundos se amplia e define-se que os documentos devem ser agrupados de acordo com as unidades administrativas que os criaram (e não de acordo com a natureza das instituições que os criaram, como proposto na França) e que o arranjo dado aos documentos pelos órgãos de criação deve ser mantido. A esse princípio é dado o nome de Provenienzprinzip, ou princípio da proveniência.

Ainda em 1881, é enunciado o Registraturprinzip, princípio que estabelecia que os documentos de cada órgão deveriam ser mantidos, no arquivo de custódia, na ordem dada pelo serviço de registro do órgão, e não reorganizados por grupos de assunto, como era recorrente na França (SCHELLENBERG, 2006). Ainda, segundo o autor, ao contrário do sistema francês, segundo o qual os documentos de um fundo eram reorganizados para atender às pesquisas, o sistema prussiano estabeleceu a manutenção de registros segundo as funções administrativas dos órgãos governamentais, dando origem ao princípio da ordem original.

$\mathrm{Na}$ teoria arquivística o princípio da proveniência ainda não corresponde a uma definição específica, como nos explica Martín-Pozuelo (1996). A escarça normalização terminológica ainda é um dos problemas fundamentais da teoria arquivística, o que nos leva a uma divisão em dois princípios (proveniência e ordem original). Para alguns autores (SCHELLENBERG, 2006; EVANS, 1991) a manutenção da ordem original configura-se como outro princípio, enquanto que para outros autores, ela representa uma extensão ou um segundo grau da proveniência (CARUCCI, 1987; BRENNEKE, 1968).

O princípio da proveniência pode ser considerado, portanto, uma 
ampliação do princípio de respeito aos fundos, na medida em que engloba dois graus de proveniência: o respeito ao produtor e o respeito à ordem original dada pelo produtor.

Embora o princípio da proveniência tenha se desenvolvido de forma diferente de um país para outro enquanto resultado de distintas culturas administrativas e, apesar de uma confusão conceitual terminológica presente na literatura da área, é consenso que os documentos de arquivo são produtos de atividades desenvolvidas por pessoas físicas ou jurídicas e compreender isso significa compreender a rede de relações entre os objetos (documentos de arquivo), os agentes (produtores) e as funções. Por isso, um documento de arquivo não pode ser concebido como um elemento isolado.

Compreender um documento é saber exatamente por quem foi criado, em qual estrutura e sob qual procedimento. Em outras palavras, quais as suas origens, para quem, quando e onde. Segundo Duchein (1983, p. 67), as respostas para essas perguntas estão no conhecimento do fundo documental, na compreensão de sua totalidade.

Percebe-se, assim, que a reunião de documentos advindos de uma mesma proveniência compõe um grupo de documentos que mantêm um conhecimento específico sobre determinada pessoa ou instituição. No entanto, essa reunião é compreendida como um momento final, advinda de uma série de procedimentos que possibilitam ao arquivista reunir esse conhecimento específico em um fundo (primeiro definiens). Nesse sentido, considera-se o conhecimento da forma documental - adquirido por meio da análise diplomática - como o segundo definiens do conceito de conhecimento arquivístico, necessário para a compreensão dos conjuntos documentais que formarão o fundo.

\subsubsection{O segundo definiens: o conhecimento da forma documental}

Nos últimos trinta anos, a Arquivologia é convidada a repensar seus princípios e metodologias, a fim de dar conta da produção, organização e uso de documentos em meio digital. Nesse contexto muito específico, emergem correntes de pensamento em diferentes países, como a Arquivística Pós- 
Moderna e a Arquivística Integrada, no Canadá, a Arquivística Pós-Custodial, em Portugal, a abordagem do records continuum, na Austrália, e a Diplomática Arquivística, na Itália.

No tocante a essa última, observa-se que seus estudos têm fundamentado as metodologias de organização arquivística desde a década de 1960, quando houve uma primeira identificação do objeto de estudo da Arquivologia com aquele da Diplomática, a saber, os documentos de arquivo.

Em uma nova realidade de produção, organização e uso de informações faz-se necessário estabelecer as razões que estão por trás da criação dos documentos, qual a relação dos criadores com eles e, assim, quais as intenções por trás da ação de registrar a informação. Para tanto, o estudo a partir do documento, com base na Diplomática e em seu método, torna-se o mais seguro para o arquivista. Poder estabelecer quem produz, por quê e para que, por meio do estudo da forma documental é a grande contribuição da Diplomática para os estudos arquivísticos atuais.

Distinguir os documentos (urkunde, acte) falsos dos autênticos sempre foi o objetivo da Diplomática e a razão pela qual seus estudos foram desenvolvidos. Tanto os diplomatistas clássicos, quanto os modernos tinham como objetivo analisar os documentos que serviam de testemunho para a verificação de fatos, ora com um objetivo prático-jurídico, ora com um objetivo de contar os fatos dos passados em uma perspectiva historiográfica. Para fazê-lo, ou seja, para compreender o documento enquanto autêntico ou falso fez-se necessário, antes de mais dada, o estudo de sua forma.

Nesse contexto, podemos entender a Diplomática como uma arte crítica, que busca, por meio da compreensão da forma documental, discernir a autenticidade e/ou falsidade do documento. Logo, a Diplomática é a arte que estuda a essência do documento, ou seja, sua forma.

Especificamente no tocante à forma, pode-se dizer que esta estrutura o documento fornecendo os elementos necessários e as regras de composição para que um determinado negócio jurídico possa ser reconhecido como idôneo para a atuação de sua função. Assim, o documento diplomático terá a mesma forma quando houver a mesma problemática jurídica. Essa forma será 
determinada por regras estabelecidas pelo Direito.

Essas regras determinam os modelos aos quais os atos devem se conformar. Elas agem principalmente sobre o teor, propondo ao redator os termos técnicos, as expressões ou frases já feitas, os tipos de composição fornecidos por meio dos formulários. Elas ordenam também todo o aspecto exterior, determinam rigorosamente o tipo de suporte material da escritura, a tinta, a própria escritura, o modo de inserir os sinais de validação (DUMAS, 1932, p. 30, tradução nossa).

Ainda segundo o autor, a forma dos atos é tudo aquilo que é condicionado por regras. Essas regras determinam os elementos intrínsecos e extrínsecos do documento, ou seja, o texto propriamente dito, os caracteres aplicados aos documentos que Ihes conferem força probatória, assim como os meios para redigi-lo.

A forma é, portanto, determinante para a criação de um documento juridicamente válido e relevante. Segundo Sickel, a forma do documento diplomático deve seguir uma estrutura composta por protocolo inicial, texto e protocolo final. "Eu chamo texto a parte central do documento e formulário ou protocolo o conjunto de fórmulas inicias e finais. Texto e protocolos são, portanto, os caracteres intrínsecos documentos" (SICKEL, 1867, p. 107, tradução nossa).

Os protocolos agem como uma moldura para o documento, enquanto que o texto apresenta o conteúdo, propriamente dito, conforme observado no quadro abaixo:

Quadro I - Método para análise de documentos diplomáticos

\begin{tabular}{|l|l|}
\hline PROTOCOLO INICIAL & 1) Invocação (die Invocation) \\
& (2) Nome e título (Name und Titel) \\
\hline TEXTO & (1) Nome, títulos e predicados do \\
destinatário (Inscription/ adress) & (2) Preâmbulo (Arenga) \\
& (3) Notificação (Promulgatio) \\
& (4) Exposição (Narratio) \\
& (5) Dispositivo (Dispositio) \\
& (6) Forma de corroboração \\
& (Corroborationsformeln) \\
& (7) Anúncio dos sinais de validação (Die \\
& Ankündigung des Siege/s) \\
\hline PROTOCOLO FINAL & (3) Assinatura (Unterschrift) \\
& (4) Datas (Datierung) \\
& (5) Precação (die Apprecation) \\
\hline
\end{tabular}

Fonte: Elaborado por Tognoli (2014), com base em Sickel (1867, p. 107) 
Nos protocolos inicial e final constam as informações acerca do contexto de criação do documento, como seu produtor, datas e sinais de validação, enquanto que no texto tem-se as informações acerca do assunto e da atividade do documento (exposição e dispositivo). Essa divisão entre texto e protocolos, preconizada por Sickel (1867), permitiu à Diplomática o estabelecimento de um método próprio de análise de documentos, elevando-a ao status de disciplina.

No entanto, vale a pena ressaltar que esse método estava voltado aos documentos diplomáticos medievais, ou seja, aos escritos solenes de natureza jurídica e redigidos sob a observância de regras determinadas por normas.

Na década de 1960, o arquivista Robert-Henri Bautier (1961), ao defender uma expansão da problemática da Diplomática a todos os documentos de arquivo, sem limitação cronológica ou jurídica, propôs uma ampliação do objeto para além daqueles testemunhos redigidos segundo a observação de formas determinadas que garantem ao documento natureza jurídica e força probatória.

Para o autor o documento deveria ser compreendido em função do fundo ao qual pertencia, advogando pela sua compreensão enquanto documento de arquivo - documentos que fazem parte de um mesmo fundo e que guardam relações orgânicas entre si -, o que garantiria ao diplomatista uma melhor compreensão do contexto no qual o documento foi gerado, uma vez que as fontes são claramente maiores.

Para Bautier (1961), um documento não poderia ser verdadeiramente compreendido fora do contexto ao qual pertencia. Assim como os arquivistas têm muito clara essa relação, os diplomatistas também deveriam apoiar-se na perspectiva de fundo e conjunto, oferecidos pela ciência dos arquivos.

[...] A crítica dos documentos é surpreendentemente facilitada pela sua aproximação aos documentos anteriores e posteriores a eles, assim como pela reunião de peças de um mesmo dossiê [...] Nós estamos convencidos que os diplomatistas seriam muito mais conscientes deste aspecto se eles tivessem sempre acreditado na noção de que o documento diplomático é essencialmente um documento de arquivo, quer dizer, uma peça em um conjunto, um elemento em um fundo (BAUTIER, 1961, p. 212, tradução nossa).

A perspectiva de uma disciplina mais contemporânea, voltada aos documentos de arquivo, encontrou fulcro nas discussões que se seguiram sobre a produção, organização e preservação de documentos em um novo contexto 
tecnológico quando, em 1989, Luciana Duranti (2013) propôs novos usos para a Diplomática. A partir da aplicação da crítica diplomática aos documentos contemporâneos na América do Norte a autora constatou sua aplicabilidade também no contexto digital, dando início ao Projeto InterPARES.

A Diplomática, no contexto da Arquivologia, permite que o arquivista chegue à compreensão do conjunto documental e de seu contexto a partir da crítica do documento. Desse modo, a análise do arquivista desloca-se desde o contexto documental imediato do material que examina até o amplo contexto funcional dos criadores de documentos e de suas relações. Essa análise, assim como a crítica de um documento medieval, é feita por meio do estudo da forma do documento, que se manifesta em seus elementos internos e externos (DURANTI, 2013).

Buckland (2018), em sua teoria do documento, afirma que qualquer interação ou atributo compartilhado pode ser utilizado para indicar uma relação que dará sentido ao documento. Neste contexto, o estudo dos elementos presentes na forma do documento, especialmente os intrínsecos, nos permite vislumbrar três relações importantes: uma entre o documento e o procedimento que lhe deu origem, que reflete sua natureza orgânica; outra entre os próprios elementos intrínsecos, compostos pelos protocolos e pelo texto e que formarão um discurso harmônico que dará sentido ao documento; e a relação entre o conjunto de documentos que pertencem à mesma atividade e a mesma forma documental, e que dará origem aos tipos documentais e às séries.

Consequentemente, entende-se que a aplicação do método diplomático fornece elementos essenciais para que se possa conhecer o documento de arquivo para além de sua forma, possibilitando uma aproximação com seu contexto de produção e natureza.

Para Rogers (2015) a análise diplomática é um processo de abstração e sistematização, em que o documento de arquivo é desconstruído para que sejam identificados e localizados os elementos que revelam sua proveniência, relações, confiabilidade e autenticidade.

Os arquivistas começam, portanto, a compreender o método diplomático como uma "nova" ferramenta para auxilia-los na gestão da documentação 
gerada nos processos administrativos. Ao estudar as relações entre a Diplomática e a Arquivologia e sua relevância para os estudos da gênese documental, Rodrigues (2016) estabelece a necessidade de identificar os documentos em seu contexto de produção a fim de planejar sua produção e tratamento.

Em vista disso, depreendemos que a partir do exame das partes o arquivista chega ao exame do todo, do contexto, do processo, para determinar as relações existentes entre um e outro. Os resultados alcançados com a identificação do documento por meio da análise diplomática irão subsidiar os processos de organização e representação, uma vez que acreditamos que as informações coletadas durante esse processo, uma vez amalgamadas e compreendidas em um contexto específico, constituem um conhecimento arquivístico, ou seja, um conhecimento adquirido a partir do estudo do documento e de suas relações com o produtor e com o procedimento que o gerou.

Neste sentido, apontamos o método diplomático e sua aplicação como definidores do segundo definiens do conceito de conhecimento arquivístico, a forma documental, que irá se efetivar a partir da aplicação da identificação arquivística enquanto uma metodologia capaz de fornecer elementos para a compreensão do que entendemos como o terceiro definiens para o conceito, o contexto de produção, como será apresentado a seguir.

\subsection{O TERCEIRO DEFINIENS: O CONHECIMENTO DO CONTEXTO DE PRODUÇÃO DOS DOCUMENTOS}

Com a explosão documental gerada após a Segunda Guerra Mundial, fezse necessário estudar os documentos em seu nascimento, visando à racionalização da produção. Neste contexto, emergiu o conceito de gestão de documentos, que visava controlar o documento desde o momento de sua produção até sua destinação final, qual seja, eliminação ou guarda permanente.

A gestão de documentos originou-se na impossibilidade de se lidar, de acordo com "moldes tradicionais", com as massas cada vez maiores de documentos produzidos pelas administrações públicas americanas e canadenses. Assim, a partir das soluções apontadas por comissões governamentais nomeadas para a 
reforma administrativa dos Estados Unidos e do Canadá, no final da década de 40 do século XX, foram estabelecidos princípios de racionalidade administrativa, a partir da intervenção nas etapas do ciclo documental, a saber: produção, utilização, conservação e destinação de documentos (FONSECA, 1998, p. 38).

Segundo Rodrigues (2015) a gestão de documentos se caracteriza como um conjunto de procedimentos aplicados para controlar os documentos arquivísticos durante todo o seu ciclo de vida, incidindo sobre o momento da produção e acumulação na primeira e segunda idade, ou seja, nos arquivos correntes e intermediários. Ainda segundo a autora, a introdução de programas de gestão de documentos na teoria arquivística, levou à necessidade da criação de metodologias para resolver os problemas observados nos arquivos.

Nasce, assim, na Espanha, em 1980, o conceito da identificação como uma ferramenta para a análise do documento e de seu órgão produtor, aplicada às massas documentais acumuladas, visando à elaboração de propostas para a avaliação e classificação dos documentos de arquivo. Rodrigues (2015) destaca que a identificação é uma tarefa de pesquisa com dois objetos de estudo: órgão produtor e documento.

Trata-se de uma tarefa de pesquisa sobre os elementos que caracterizam os dois objetos de estudos da identificação: órgão produtor, analisando o elemento orgânico (estrutura administrativa) e o elemento funcional (competências, funções e atividades) e a tipologia documental, estudo que se realiza com base no reconhecimento dos elementos externos, que se referem à estrutura física, à forma de apresentação do documento (gênero, suporte, formato e forma) e internos (RODRIGUES, 2015, p. 72).

Rodrigues (2008) ressalta, ainda, que a necessidade de identificar documentos em seu contexto de produção para planejamento de sua criação/produção e tratamento técnico de sua acumulação nos arquivos conduziu a área à reflexão sobre a Identificação como processo arquivístico e às discussões sobre a posição que esta ocupa no âmbito das metodologias arquivísticas.

A identificação é considerada uma tarefa de natureza intelectual com o objetivo de determinar a identidade do documento de arquivo, reconhecendo os elementos que o individualizam e o distinguem em seu conjunto (RODRIGUES, 2015). Para tanto, recorre-se à análise documental, subsidiada pelo método 
diplomático, para determinar o tipo documental, e à análise contextual, subsidiada pelo estudo da documentação constitutiva do órgão produtor (informações coletadas em regimentos, estatutos, organogramas), para determinar seu elemento orgânico (áreas administrativas que o configuram) e funcional (competências, funções, atividades e tarefas).

O conhecimento gerado a partir das informações coletadas sobre o órgão produtor juntamente ao processo analítico dos documentos por ele produzidos, configuram um conhecimento específico, novamente, um conhecimento arquivístico. Por esse motivo, acredita-se que a metodologia da identificação, subsidiada pelo método diplomático, subsidia o conhecimento do contexto de produção dos documentos, considerado aqui como o último definiens do conceito de conhecimento arquivístico.

\section{CONSIDERAÇÕES}

O presente trabalho buscou aproximar os estudos arquivísticos da organização do conhecimento, uma vez que consideramos essa última como um campo integrador que pode contribuir para os processos de organização no domínio arquivístico (especialmente para os processos de classificação e descrição). Assim, para atingir esse objetivo, buscamos definir o conceito de conhecimento arquivístico, uma vez que entendemos que os processos de classificação e descrição incidirão sobre este.

Compreendendo o conceito como um constructo dinâmico e social que não pode ser entendido isoladamente e à parte dos interesses e teorias que motivaram sua construção (HJØRLAND, 2009), utilizamos a teoria do conceito da Dahlberg para conceber o conceito de conhecimento arquivístico e chegamos à seguinte equação de sentido: definiendum $=$ def1 + def2 + def3, ou seja, conhecimento arquivístico $=$ conceito de fundo + conhecimento da forma documental + conhecimento do contexto de produção.

Consideramos, portanto, que o conhecimento arquivístico pode ser concebido a partir do conceito de fundo (sobre o qual incidirão todos os processos de organização), caracterizado a partir da reunião e análise de documentos produzidos por uma mesma pessoa ou instituição, com base no 
método diplomático enquanto suporte para a metodologia da identificação arquivística.

As informações coletadas por meio da aplicação do método diplomático, para analisar a tipologia documental, e dos fundamentos teóricos do Direito e da Administração para estudar a estrutura e funcionamento do órgão produtor resultado da identificação arquivística - constituir-se-ão um conhecimento arquivístico específico sobre aquele conjunto documental.

Assim, considera-se que o conhecimento arquivístico define-se a partir da reunião de três facetas indivisíveis nas quais o vínculo arquivístico está contemplado.

\section{REFERÊNCIAS}

ALENCAR, M. F; CERVANTES, B. M. N. A semântica na organização do conhecimento arquivístico: o caso dos tesauros funcionais. In: BARROS, T. H. B; TOGNOLI, N. B. (orgs). Organização do Conhecimento responsável: promovendo sociedades democráticas e inclusivas. Estudos avançados em Organização do Conhecimento, v. 5. Belém: Ed. UFPA, 2019. p. 287-297.

BARROS, T. H. B.; MORAES, J. B. E. Archival classification and knowledge organization: theoretical possibilities for the archival field. In: NEELAMEGHAN, A.; RAGHAVAN, K.S (org.). Categories, contexts and relations in knowledge organization. Wurzburg: Ergon-verlag Gmbh, 2012. p. 272-276.

BAUTIER, R. H. Leçon d'ouverture du cours de diplomatique à L'Ecole des chartes. Paris: Bibliothèque de l'Ecole des Chartes, 1961.

BRENNEKE, A. Archivistica: contributo alla teoria ed ella storia archivistica europea. Milão: [s. n.], 1968.

BUCKLAND, M. Document theory. Knowledge Organization, v. 45, p. 425-36, 2018.

CARUCCI, P. Il documento contemporaneo: diplomatica e criteri di edizione. Roma: La Nuova Italia Scientifica, 1987.

DAHLBERG, I. Teoria do conceito. Ci. Inf., Rio de Janeiro, vol. 7, n. 2, p. 101107, 1978.

DUCHEIN, M. Theoretical principles and practical problems of respect des fonds in Archival Science. Archivaria, v. 16, p. 64-82, 1983. 
DUMAS, A. La Diplomatique et la forme des actes. Le Moyen Age, n. 3, p. 5$31,1932$.

DURANTI, L. From classical diplomatics to digital diplomatics. Apresentação. Oslo, 2013.

ESTEBAN NAVARRO, M. A. La representación y la organización del conocimiento en los archivos. Zaragoza: Universidad de Zaragoza, ISKOEspaña, 1995. p. 65-90.

EVANS, F. B. Records and administrative processes: retrospects and prospects. Janus, n. 1, p. 29-37, 1991.

FONSECA, M. O. K. Informação, arquivos e instituições arquivísticas. Arquivo \& Administração, v. 1, n. 1, 1998. Disponível em:

http://hdl.handle.net/20.500.11959/brapci/21021. Acesso em: 29 abr. 2019.

GARCIA MARCO, F. J. Fundamentos de organizacón y representacion documental: aportaciones de la archivística. Revista General de Información y Documentación, Madrid, v. 5, n. 2., 1995.

GUIMARÃES, J. A. C. Organização do Conhecimento: passado, presente e futuro sob a perspectiva da ISKO. Informação \& Informação, Londrina, v. 22, n. 2, p. 84-98, maio/ago., 2017. Disponível em:

http://www.uel.br/revistas/uel/index.php/informacao/article/view/31443/21993. Acesso em: 03 mar. 2019.

GUIMARÃES, J. A. C.; TOGNOLI, N. B. Provenance as a domain analysis approach in archival knowledge organization. Knowledge Organization, v. 42, n. 8, p. 562-569, 2015.

HJØRLAND, B. Concept theory. Journal of the American Society for Information Science and Technology, v. 60, p. 1519-1536, 2009.

HJØRLAND, B. Domain Analysis in information science: eleven approachestraditional as well as innovative. Journal of Documentation, v. 58, p. 422-62, 2002.

HJØRLAND, B. What is Knowledge Organization (KO)? Knowledge Organization, v. 35, n.2/3, p. 86-101, 2008.

LEHMKUHL, C. S.; LINDEN, L. L.; BARROS, C. M.; SILVA, E. C. L.; VITAL, L. P. Sistemas de organização do conhecimento e Arquivologia: diálogos possíveis. In: BARROS, T. H. B; TOGNOLI, N. B. (org). Organização do Conhecimento responsável: promovendo sociedades democráticas e inclusivas: estudos avançados em organização do conhecimento. Belém: Ed. UFPA, 2019. p. 58-66.

MARTÍN-POZUELO, M. P. C. La construcción teórica en archivística: el principio de procedencia. Madrid: Universidad Carlos III de Madrid, 1996. 
RABELLO, R. História dos conceitos e ciência da informação: apontamentos teórico-metodológicos para uma perspectiva epistemológica. Encontros Bibli: Revista Eletrônica de Biblioteconomia e Ciência da Informação, v. 13, n. 26, p. 17-46, 2008. DOI: 10.5007/1518-2924.2008v13n26p17. Acesso em: 03 mar. 2019.

RODRIGUES, A. C. Diplomática contemporânea como fundamento metodológico da identificação de tipologia documental em arquivos. 2008. Tese (Doutorado em História Social) - Faculdade de Filosofia, Letras e Ciências Humanas, Universidade de São Paulo, São Paulo, 2008.

DOI:10.11606/T.8.2008.tde-27112008-151058. Acesso em: 03 mar. 2019.

RODRIGUES, A. C. Diplomática e Arquivística: diálogos para a construção do método de identificação da tipologia documental. In: XVII ENCONTRO NACIONAL DE PESQUISA EM CIÊNCIA DA INFORMAÇÃO. Descobrimentos da Ciência da Informação. 2016, Salvador. Anais [...]. PPGCI/UFBA. p. 869881. Disponível em:

https://drive.google.com/file/d/OB7rxeg_cwHajMW9ZV0xFZHBhTnc/view. Acesso em 04 jun. 2018.

RODRIGUES, A. C. Identificação como requisito metodológico para a gestão de documentos e acesso à informações na administração pública brasileira. Ciência da Informação, [S. I.], v. 42, n. 1, jan. 2015. Disponível em: http://revista.ibict.br/ciinf/article/view/1395/1573. Acesso em: 03 mar. 2019.

RODRIGUES, A. C. Identificação como requisito metodológico para a gestão de documentos e acesso às informações na administração pública brasileira. Ciência da Informação, v. 42, n. 1, 2013. DOI: 10.18225/ci.inf..v42i1.1395 Acesso em: 29 out. 2019.

ROGERS, C. Diplomatics of born digital documents: considering the documentary form in a digital environment. Records management Journal, v. 25, n. 1, p. 6-20, 2015. DOI: 10.1108/RMJ-03-2014-0021. Acesso em: jun. 2016.

SCHELLENBERG, T.R. Arquivos modernos: princípios e técnicas. 6. ed. Rio de Janeiro: FGV, 2006.

SICKEL, T. V. Beiträge zür Diplomatik. Viena: Gerold in Komm, 1867.

TOGNOLI, N. B. A construção teórica da Diplomática: em busca de uma sistematização de seus marcos teóricos como subsídio aos estudos. São Paulo: Cultura Acadêmica, 2014.

TOGNOLI, N. B.; GUIMARÃES, J. A. C.; TENNIS, J. T. Diplomatics as a methodological perspective for archival knowledge organization. NASKO, Washington, v. 4, p. 204-212, out. 2013. Disponível em: http://dx.doi.org/10.7152/nasko.v4i1.14661. Acesso em 11 Ago. 2015. 
TOGNOLI, N. B.; RODRIGUES, A. C.; GUIMARÃES, J. A. C. Archival Knowledge: conceptual frameworks for a recent terminology in the KO domain. Knowledge Organization, v. 46, n. esp. 2019.

\title{
DEFINING ARCHIVAL KNOWLEDGE: CONCEPTUAL FRAMEWORKS
}

\begin{abstract}
Introduction: Despite having the principle of provenance as its guiding element, the archival knowledge organization still prescinds, for conceptual purposes, of greater clarity of its object - the archival knowledge - a fundamental aspect for the sedimentation of the archival studies and of its discursive community in the scope of KO. Objective: This article aims to define a conceptual framework to archival knowledge by using Dahlberg's concept theory. Methodolody: Literature review about archival knowledge organization and the concept theory. Results: The research established the nominal concept or definiendum - archival knowledge - seeking to analyze its real definition, composed by three inseparable definiens: the concept of fonds, the knowledge of documentary form and the knowledge of document creation context. Conclusion: At the end, it demonstrates that archival knowledge is defined as being a reunion of three indivisible facets in which the archival bond will be contemplated.
\end{abstract}

Descriptors: Knowledge organization. Concept theory. Archival knowledge. Diplomatics.

\section{DEFINIENDO EL CONOCIMIENTO ARCHIVÍSTICO: ESTRUCTURAS CONCEPTUALES}

\begin{abstract}
RESUMEN
Introducción: A pesar de tener el principio de procedencia como elemento guía, la organización del conocimiento archivístico aún carece de una mayor claridad conceptual de su objeto, el conocimiento archivístico, aspecto fundamental para la sedimentación de los estudios archivísticos y su comunidad discursiva dentro de la organización del conocimiento. Objetivo: Este artículo tiene como objetivo definir uma estrutura conceptual para el conocimiento archivístico a partir de la teoría del concepto de Dalhberg. Metodología: Revision de la literatura acerca de la organizacíon del conocimiento archivistico e de la teoria del concepto. Resultados: En este sentido, se establece un concepto nominal o definiendum - el conocimiento archivístico - buscando analizar su definición real, compuesta por três definiens: el concepto de fundo, el conocimiento de la forma documental y el conocimiento del contexto de producción del documento. Conclusiones: Al final, se reconoce que el conocimiento archivístico se puede definir como una reunión de tres facetas inseparables en las que se contemplará el vínculo archivístico.
\end{abstract}

Descriptores: Organización del conocimiento. Teoria del concepto. Diplomatica. Conhecimiento archivístico. 